\title{
Access and quality in South African higher education: the twin challenges of transformation
}

\author{
S. Akoojee \\ Human Sciences Research Council \\ e-mail: sakoojee@hsrc.ac.za \\ M. Nkomo \\ University of Pretoria \\ e-mail: nkomom@hakuna.up.ac.za
}

\begin{abstract}
Higher Education transformation in South Africa requires a synergy of creative strategies to engage issues of redress. Access to higher education remains one mechanism for achieving this in South African higher education. While there is clearly a need to enable access by improving student success (access with success), as opposed to simply ensuring their participation (access as participation), the adequacy of these initiatives needs to be evaluated in the context of institutional transformation. By introducing a quality assurance framework, institutions can ensure that access initiatives are institutionalised. Conceptions of access, however, need to be situated within appropriate definitions of quality. This would enable institutions to track the responsiveness of measures to achieve national transformational objectives. It is argued that current Academic Development (AD) initiatives as a means of achieving 'access with success' can only deal marginally with the transformation agenda in South Africa. It is proposed that a comprehensive quality assurance framework with embedded commitment to access is likely to respond appropriately to national development prerogatives of higher education access.
\end{abstract}

\section{INTRODUCTION}

Increased student access to higher education institutions has been associated with the recent massification of higher education. The concern with greater participation is not new in South Africa but it has become an urgent imperative after the demise of apartheid. There has been a similar drive at the global level in recent times. International calls for greater access was evidenced in the UNESCO World Conference on Higher Education in 1998, which, in its preamble, called for 'equality of access' (UNESCO 1998). It is therefore not surprising that participation and particularly the success of these participation strategies have recently dominated the discourse. This, together with the structural reorganisation and the various debates around financing and access have foregrounded access as a key component of successful HE transformation (see Pandor 2005). There is an undeniable national need at South African institutions to enable not only the 
participation of women and black students but to ensure that these participation strategies lead to successful outcomes. Recent research indicates significantly poorer levels of both adjustment of black students at previously white institutions (Sennett et al. 2003), decline in performance of black students as compared to their white counterparts and the consequent effect on their dropout rates (Agar1990; Van Heerden 1995; Kegee et al. 1997; Mabokela 1997; Cherian and Cherian 1998).

Equity and redress are important imperatives for a society attempting to transform (Dowling 1999, 10). Within this perspective, access is critically placed to achieve appropriate notions of equity and redress. Access measures can be considered a compelling priority in the light of the current need for equity and redress. The transformation of a society struggling to undo the ravages of its past requires that black South Africans be provided opportunities to realise their potential. The challenge for the success of strategies, however, lies in the need to balance issues of institutional autonomy with the national imperatives of efficiency, equity and redress.

Current policy has suggested that Academic Development (AD) can be used as a meaningful strategy to increase the success of access initiatives (see DoE 2001). This article argues that Academic Development as an institutional redress and access mechanism is considered wanting. The article takes as a point of departure the view that by introducing an appropriate quality assurance framework, institutions can ensure that access initiatives are institutionalised. It is argued that the development of internal access strategies will enable the issue to be effectively tackled and will enable the development of effective monitoring. Strategies employed by institutions could then be evaluated against national benchmarks by external national quality assurance agencies. ${ }^{1}$ It is also assumed that while quality is an important component in the drive to achieve an overall reorientation of institutional focus, that it is not by itself a panacea for transformation. There are undoubtedly other mechanisms that can be deployed, but it seems eminently reasonable to presume that quality assurance is crucial.

The first part of the article provides a context for understanding access initiatives from a historical perspective. It offers a brief analysis of South African experiences with student access, which is used as a backdrop for understanding the current South African context. The article then explores contemporary concerns regarding access and examines the way in which the academic development strategy contained in national policy needs to be reviewed to enable effective access. Borrowing from Bergquist's (1995) notion of 'quality with access', the article provides a means by which to realise appropriate access at the institutional level.

\section{ACCESS, QUALITY AND STANDARDS ISSUES NOT NEW: A BRIEF HISTORICAL OVERVIEW}

Concern about low levels of throughput and high attrition rates especially among first-year university students are not a uniquely post-1994 phenomenon. The 
concern dates back to the heyday of apartheid. At that time, however, it tended to be almost exclusively focused on the high attrition rates of white students entering first year at university. One of the first studies to examine the high failure rate was commissioned in 1936 by the then Minister of Education, J. H. Hofmeyr, conducted by the National Bureau for Education and Social Research. It surveyed 8000 white students entering South African universities over a six-year period. Its main finding was that almost 47 per cent of all first-year students failed in at least one subject and 25 per cent in more than one subject. This study debunked the notion that it was the 'youthfulness' of students that was the main cause of the high failure rate, and proffered instead that the reason for this was a mix of the transition from school to university and the inadequacy of the university teaching system. ${ }^{2}$ Again, in the 1950s, the Transvaal Education Department conducted investigations that corroborated the earlier findings (Malherbe 1965, 478). This study analysed the differences in performance of students in different faculties within universities, and between different universities. Results showed that in 1956 the average first year failure rate was as high as 38 per cent at one institution (of six studied) to 15 per cent at the lower spectrum, with considerable variation between and within the various disciplines (Malherbe 1965, 478).

There is also evidence that access to the sciences was more difficult because of the high failure rate. In the Transvaal Education Department Report (Malherbe 1977), more failures (up to $56 \%$ at one institution) were recorded in the 'applied biological sciences' than in other disciplines. Agriculture and forestry, for instance, were confirmed to be lower at between 32 per cent and 38 per cent. While there were a number of individual studies into the high attrition rates, for instance, the Psychology Department of the University of Stellenbosch (1954), the study by H. S. Steyn (Malherbe 1977, 487) commissioned by the Joint Matriculation Board in 1963 elicited widespread public debate at that time. This study found that only 55 per cent of students entering the eight South African residential universities eventually succeeded in obtaining a first degree. There was also no correlation between school and university academic performance. For instance, only 62 per cent of first class matriculants accepted in the science faculty succeeded in achieving a qualification. The national concern that these figures engendered is described as follows:

. . . the fact remains that the drop-out rate of $45 \%$ of all university students $(49 \%)$ of which are men is nothing less than a national disaster, not necessarily because these students should obtain degrees, but because of the lamentable waste of effort. These are strong words, but unless we are shocked into action there is a very real danger that familiarity with this situation may breed acceptance (Malherbe1977, 487).

The same Steyn Report also found that the rate of success at university was not in any way related to their achievement at school. Various reasons were cited at various times for the high attrition rate. These included poor school preparation and the 'weaknesses' of the university teaching and learning system (Malherbe 
1977, 485). In an attempt to stem this tide, measures suggested included school level quality improvement. It is interesting that rather than restricting admissions, there was instead a call for a broader basis of screening as an alternative to the school-leaving matriculation. ${ }^{3}$ It was evident that the suggestions for reducing attrition did not in any way require reducing in absolute numbers those admitted to institutions. This would have had the effect of reducing in absolute terms the numbers of those admitted to these institutions. Furthermore, there was no concern about standards having been compromised as a result of an 'open admissions policy' as these were overshadowed in large measure by the need to increase success. In fact, if anything, funding was increased in an attempt to correct the situation to enable success.

It was evident that access was also accompanied by an economic imperative. It was driven by a need to allow more white people to become managers and supervisors. Thus it was not surprising that the Steyn Report (1963 cited in Malherbe 1977), which was referred to the National Advisory Education Council, recommended against more stringent admission criteria since by 'putting up the standards, potentially good white university material might be excluded from a university training and that thereby the much-needed trained manpower in the country might be limited' (Malherbe 1977, 495). The problem of white attrition is made particularly more daunting at the time when we consider the access to, and funding for, the university system at the time. According to Malherbe, South Africa was sending a bigger proportion of its white population to university than any other country (Malherbe 1977, 494). This 'virtually' unhindered access (for whites) was also associated with considerable spending on the university system ${ }^{4}$ (Malherbe 1977, 497; Subotzky 2003; HSRC 2003). It has been estimated that the cost of running the universities had increased by a factor of 64 between 1940 and 1974. For this reason, it was contended that ' . . . if looked at in relation to the size of only the White population, it (university spending) has grown to be probably the most costly for any civilised (sic) population group in the world' (Malherbe 1977, 627). Reasons offered by this source included the demand for specialised equipment and the duplication of specialities to 'satisfy local ethnic aspirations'.

In addition, the various recommendations to solve the problem of white attrition reinforced access by ensuring that the failure rate is contained. There was a call, for instance, to improve school guidance and counselling; a suggestion for a post-matriculation year in high schools; and the recommendation for the establishment of a foundation or basic year for all students. This latter proposal (Malherbe 1977) comes closest to current Academic Development measures, albeit in a much more progressive form than anything currently proposed or implemented. It called for a general formative year to be established for all students as a preparatory step for university work. It also involved the teaching of a broad fundamental curriculum, without specialisation, which would enable students to be '... in a better position to decide in what direction his metier 
lies than under the present conditions where he is rather abruptly translated from school into a different and strange world of academic methods and objectives, 5 (Malherbe 1977, 492).

It is self evident that during the apartheid period, university access for black people did not feature as a necessary or appropriate policy option in the same way and degree accorded to white access. At the time of the Eiselen Commission on Native Education in 1951 (Eiselen 1951), there was only one residential university for Africans, the South African Native College at Fort Hare, with an enrolment of only 343. In addition, a number of 'non-whites' made up 'over a quarter' of the total student population at the distance education institution, University of South Africa (UNISA). Additionally, while there was very limited enrolment at some English universities, no blacks were admitted to Afrikaans institutions (Moodie 1994). This racial discrimination equivalent in higher education, introduced through the so-called Extension of University Education Act (1959) did not signal a shift from the past. Although the legislation expanded access for blacks to higher education, it did so on a racial and ethnic basis. The need for this was underpinned by economic considerations. South Africa's industrial expansion in the period required skilled personnel, which the racially skewed university structure in particular was not able to meet. Legislation established separate universities for Indians and Coloureds as special groups and designated three institutions for Africans: University of Fort Hare, University of the North and University of Zululand (Nkomo 1984). There was also an open door for black access to white institutions only if courses were not offered in their institutions and with the written permission of the Minister in each case. Thus, while a large mass of the population were denied access, economic imperatives under apartheid left some room for selected black people to access institutions of higher education.

Black student attrition from universities and a system that denied them admission can only be surmised by extrapolation from existing evidence. Malherbe $(1977,37)$, for instance, points out that the dropout rate in the non-white sector was expected to be more pronounced as a result of what he referred to as a 'whiteoriented examination system'. He also inferred that, since the quality and qualifications of 'non-white' teachers at schools and universities was lower than those prevailing in the white institutions, the dropout rate was likely to be much more serious.

\section{ACCESS AND TRANSFORMATION IN CONTEMPORARY SOUTH AFRICAN HIGHER EDUCATION}

Access is a political imperative in present-day South Africa. Official pronouncements have ensured that there is a political agenda that requires increased access for disadvantaged groups. The Education White Paper of 1997 set the basis for the envisaged transformation of higher education. It states:

South Africa's transition from apartheid and minority rule requires (that) existing 
practices and values are viewed anew and rethought in terms of their fitness for a new era. ... In South Africa today, the challenge is to redress past inequalities and to transform the higher education system to serve a new social order, to meet pressing national needs, and to respond to new realities and opportunities (emphasis added) (DoE 1997).

Transformation requires that the ethos that prevailed at higher education institutions (HEIs) in the past needs to be replaced with a new democratic culture directed at actively undoing race-based separation. In this regard, the issue of access to higher education institutions remains the key mechanism by which to forge a new order.

It is contended that there are two conceptions of access discernable in South African policy since 1994 and that these offer significantly different outcomes. In the period following 1994, policy documents resolved to address the problem of access as one of increasing the participation of black learners at institutions previously denied to them. Higher Education institutions in that period adopted an 'access as participation' approach in responding to the problem. Recently, there has been a shift to an 'access with success' approach, which is designed to enable the success of black students.

The earlier 'access with participation' trend was underpinned by the political mandate of the new democracy, which required a rapid deracialisation of higher education institutions. The success of black participation at previously white institutions appeared to succeed at a superficial level. The proportion of African students at historically white institutions (HWIs) increased dramatically from 13 per cent in 1993 to 39 per cent in 1999 (Cloete and Bunting 2000). More recent figures suggest that it has increased to 46 per cent in 2000 (Subotzky 2003). Similarly, female representation also increased in the corresponding period. In 1988, women represented 42 per cent of total enrolment in higher education and this proportion had increased to 53 per cent by 2002 .

While there is still some doubt about the way in which these student numbers have increased (DoE 2001), ${ }^{6}$ the result, at least officially, reflects significant improvement in race and gender representation. However, taken in context of the numbers that enter university from the school system, there appears enough evidence to doubt the extent of black student success. A recent report suggests that at least 25 per cent of South Africa's higher education students fail to complete their studies. This attrition and wastage was estimated at about R1, 6 billion (US\$ 163 million) a year (Rossouw 2001). Furthermore, there is little black enrolment and success in key high demand disciplines, especially in science, engineering and technology (SET). ${ }^{7}$ The low SET enrolment of 28 per cent in 2000 (Subotzky 2003) although slightly increased from 25 per cent in 1999 (Cloete and Bunting 2000; DoE 2001) means that modest improvement has been made to reach the 30 per cent target set. The gender and racial disparities, however, still remain. SET enrolment is generally higher for men (53\%) than for women (47\%). In addition, 
the SET enrolment of 39 per cent for African students as compared to 45 per cent for whites suggests that this imbalance needs to be redressed. This is compounded by the excessive skewing of SET graduation rates in 2000 - 24 per cent for African as compared with 54 per cent for whites at historically advantaged institutions (Subotzky 2003b).

This failure of African students to graduate in sufficient numbers is also reflected in higher education in general. Cloete and Bunting (2000) conclude in their analysis of higher education in South Africa that in the period 1991 to 1998 '. . . many legacies of apartheid are firmly in place' (Cloete and Bunting 2000, 31). They show that the throughput rates of black students remained low, 3 per cent in the engineering field, 12 per cent in the natural sciences, and 9 per cent in medicine and engineering (Cloete and Bunting 2000). They also point out that these figures did not improve significantly between 1995 and 1998. More recent statistics confirm the trend - a 37 per cent graduation rate for African students compared to a 51 per cent for whites (Subotzky 2003).

In fundamental ways, therefore, policies have not really succeeded in achieving any real quantitative increase in black learners at higher education institutions nor have they increased their success rates. This means that a comprehensive mechanism needs to be developed to enable access to be realised. An appropriate and relevant conception of quality assurance is proposed as an alternative.

\section{POLICY EVALUATION: REVIEW OF CURRENT POLICY ON ACCESS AND ACADEMIC DEVELOPMENT}

The National Plan for Higher Education (NPHE) sets the agenda for higher education restructuring in South Africa (DoE 2001). The policy suggests strategies directed at 'access as participation' as well as 'access with success'. Specific 'access as participation' strategies range from calls for more liberal selection procedures to appeals to widen the net of national student funding in order that more disadvantaged students participate.

As regards 'access with success', specific strategies include funding of institutional Academic Development (AD) programmes, improving the quality of schooling to provide better quality of incoming students and student financial aid schemes (DoE 2001, 49). Underpinning these considerations is the view that students who enter institutions are essentially ill equipped to handle the complexities of academia, leaving institutions themselves free of the responsibility of student failure, which incidentally contrasts significantly with the Steyn recommendations of 1963 (Malherbe 1977). Thus the real redress happens elsewhere. In schools, as the proposal to improve schooling suggests; at administrative level, as the proposal to introduce student funding implies; and outside of the mainstream of the university, as suggestive of the AD strategy. In this regard, it is noted that $\mathrm{AD}$ is the only internal institutional academic redress strategy. The NPHE makes the point that the ' . . role of academic development in 
improving the efficiency of the higher education system in terms of graduate output is critical' (DoE 2001, 31). The current form of AD favoured in the NPHE includes the following:

(a) Extended curricula' rather than 'supplementary support'.

(b) The need for students to be integrated into the mainstream.

(c) The need to be responsive to all students rather than only those who would not normally be admitted (i.e. it should not be directed at black students only) and

(d) Ensuring that 'technology driven' approaches are not the preferred modus operandi to deal with disadvantage.

While this conception of $\mathrm{AD}$ differs markedly from earlier formulations dominant in the 1980s, it suffers from similar conceptual flaws. They include:

1. AD programmes are still marginal to institutional practices. It shifts the responsibility of effective teaching and learning, and by extension redress practice, to the periphery of the institution.

2. AD as a strategy sees the problem of disadvantage as lying with students as '. . . it stems from the assumption that Black students are inherently deficient ...' (Mabokela 1997, 431).

3. Legitimising $\mathrm{AD}$ suggests that institutional transformation is either not possible or realisable in the medium to long term. It serves as a programme directed to ensure institutional fit, rather than enabling institutions to adapt to their new charges.

4. The traditional race-based intake into academic development programmes suggests that it is still tainted by racial categories, despite the assurance that extended curricula are to be directed at all learners.

5. Success is indicated by enrolment rather than outcomes in keeping with the access as participation perspective.

6. AD remains an activity that cannot be expanded. The resources required would be far too excessive for use by all students.

Richardson and Fisk-Skinner (1991) provide an incisive framework for South Africa to locate various strategies in terms of the institutional commitment to diversity and the achievement of these. Figure 1 depicts an aspect of the model.

It correctly locates 'access as participation' strategies at stage 1 (reactive), which they consider necessary for achieving the diversity objective, suggestive of 'access as participation'. Stage 2 (strategic) is associated with some strategies directed at inclusion, for example, mentoring and assistance activities. It is at stage 3 (adaptive) that real institutional transformation is required. This stage requires institutions to not only react to diversity, but also to be responsive to the various communities to which they are responsible. Thus it is necessary at this level that, 


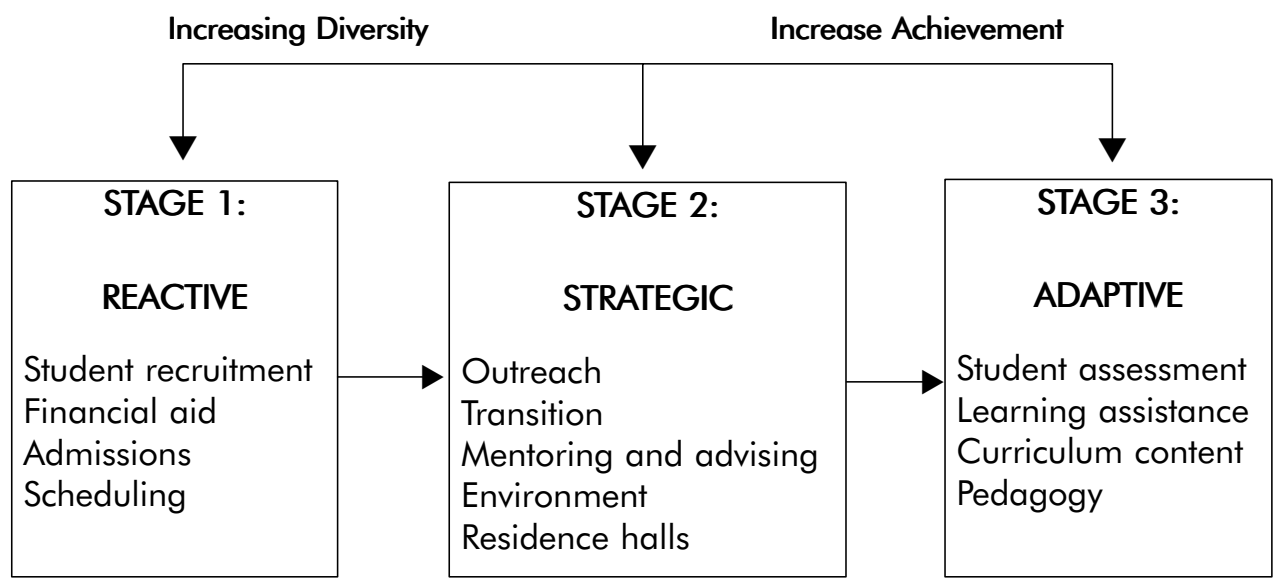

Figure 1: Source: extracted from Strategies for Diversity, from 'A model of institutional adaptation to student diversity' (Richard C. Richardson and Elizabeth Fisk Skinner 1991, 12).

'Faculty members become involved to change educational practices, curriculum content, and teaching practices to make them reflect the students they actually serve rather than their historic clientele' (Richardson and Fisk Skinner 1991, 14).

The Richardson and Fisk-Skinner model reinforces the notion that AD strategies deal only marginally with issues of institutional adaptation to student needs. AD, therefore, cannot be said to respond to this institutional transformational prerogative. It alerts us to the challenges of $\mathrm{AD}$ as a strategy. It is evident that the model if applied to South Africa suggests that AD programmes are likely to have limited impact as mechanisms for institutional transformation. It has been pointed out that more than twenty years of $\mathrm{AD}$ experiences mean that lessons learnt from them now need to be carried through to the mainstream so that what has been called the disadvantage of 'universities themselves' (Mphahlele 2001) can be addressed. There is, therefore, a need for a more co-ordinated institutional approach to ensure that access strategies are successful. The quality assurance proposal in the next section must be seen as a comprehensive counter to the academic development support mechanism suggested in the NPHE (DoE 2001).

\section{QUALITY AND TRANSFORMATION}

The literature on higher education quality assurance abounds with the emphasis on a lack of any objective criteria about what constitutes a quality product (Vroeijenstijn 1995). The 'relative' or subjective nature of the quality construct as described by Pirsig (1974) should not allow us to abrogate responsibility for its attainment.

In attempting to come to terms with the concept of quality, Harvey and Green 
(1993), have identified four 'discrete but interrelated ways of thinking about quality' considered useful in understanding conceptions of quality. They are: quality as 'exceptional or perfection' (as exclusive/gold standard); quality as 'fitness of and for purpose' (responding to identified aims); quality as 'value for money' (responding to economic rationale and efficiency), and quality as 'transformation' (moving from one state to another, implying an educational value add).

Education quality cannot be situated within politically or ideologically neutral criteria. Quality considerations are generally based on values, purposes and ends of the beholder. The reports and recommendations referred to earlier, for example the Steyn Reports (1963 cited in Malherbe 1977), are to be understood in the context of the aims of the apartheid project, that is, to restructure the education system in order to eliminate high white student attrition and to increase white student 'access with success'. The concern with university access has important implications for the way in which society is envisaged. The current need to transform is therefore not to be left to chance if the fundamental racial imbalances are to be reversed, and higher education is to achieve its 'public good' responsibilities (Badat 2001; Singh 2001).

\section{A 'transformative notion' of quality}

The proposal to introduce a transformative notion of quality is underpinned by a 'quality for purpose' perspective. It is premised on the view that there are important questions of 'ends' that need to be considered in making judgements about quality. Thus, quality in South African higher education should be understood within a context of redress, equity and access, which has as its objective the transformation of society. In this regard, Bergquist (1995, 25-26) provides a compelling argument to suggest that quality can be achieved through, and by means of, open and unfettered institutional access, and that real access cannot be achieved without attention being paid to quality. 'Quality through Access: Access with quality', is based on three premises that provide valuable direction in quality debates at institutional level. Firstly, that societal change requires a '. . . reconsideration of basic purposes and functions of institutions that require a reconsideration of issues of quality and access' (Bergquist 1995, 25). Secondly, that access is critical for the achievement of quality and that '. . the more diversified the people and resources of an educational institution are . . . the greater is the potential quality of education, research, scholarship and community service at the institution' (Bergquist 1995, 26). Thirdly, that access, and by implication quality, cannot be achieved without adequate resources.

These premises have important implications for the reconstruction of South African higher education. It would be true to say that quality and access issues cannot be separated if we are committed to transformation. There is a need to ensure that access and quality do not exist in contradiction to one another and that 
the achievement of quality is to be achieved by increasing diversity and access. It is necessary to elaborate on a conception of quality that will accommodate this perspective.

Both equity and quality have been repeatedly emphasized (Badat 2003; Nkomo 1992; Willie 2004). An equity perspective is evident in some documents. Badat $(2003,2)$ for instance suggests that 'quality and equity' should not be considered as separate parallel vectors but should be 'brought together as two sides of the same coin'.

Quality and its various dimensions need ideally to emerge from within the institution. The notion of an institutional quality assurance, which enables all sectors of the institution to define quality and tie it to access imperatives is proposed. This will enable institutions to engage with mechanisms for access. This notion of quality will therefore take on board the equity and redress challenges referred to in the White Paper (DoE 1997). It must engage institutional responsibility for access to track the extent to which the transformation challenge is being realised. Getting institutions to inform the transformational process will afford them an opportunity to report on, and track, the success of designated access mechanisms. While it is accepted that various institutional features might well reduce the potency of the ideal (Edigheji 2005), it is a necessary first step to institutional transformation which will realise access imperatives. This is clearly necessary in light of the skewed nature of staffing at South African higher education institutions. Evidence suggests that about 70 per cent of all university personnel are white and only 21 per cent African (DoE 2002).

It is anticipated that institutions themselves will develop ways to ensure that personnel will be appropriately skilled and re-skilled into new ways of engaging with the new community of students. This will include novel ways of dealing with teaching and learning provision, including peer mentoring and other strategies. It also suggests that transformation will include review of existing curricula, which are responsive to an African, rather than exclusive reference to North American or European contexts (Seepe 1999; Seepe 1998; Higgs et al. 2000). In addition, issues concerning student alienation and strategies directed at their incorporation into the institution (Seepe 1998) are much more likely to be seriously considered.

\section{CONCLUSION}

It is argued that access and quality represent the cornerstones for the successful transformation of higher education. Quality and access cannot be addressed as mutually exclusive issues. Indeed, just as there can be no 'quality without access' (Bergquist 1995), there can be no real 'access' without possibilities for success. Notions of access can be used to transform the higher education institutional landscape to respond to national priorities. Indeed, it is contended that the notion 
of 'access as participation' cannot be substituted for a notion that considers 'access with success' as an absolute precondition, but there needs to be some commitment to successful outcomes by institutions themselves.

Although there is evidence since 1994 of access approaches prevalent in the policy discourse, there is certainly at this juncture a political imperative to ensure that more and more black students are not placed into an abyss of failure. It is necessary that higher education institutions do not become arenas for thwarted ambition, as articulated by the Education Minister who pointed out the need to end the cycle of 'poor performance and inadequate intellectual challenge' (Pandor 2005). While we concur with the challenge, we argue that the responsibilities of institutions to ensure success of those whom they let in needs to be more pronounced. HEIs need to enrol students who through 'no fault of their own' are more than likely to be underprepared for the rigors of $\mathrm{HE}$ and will therefore require institution-wide measures to ensure their success.

The utility of academic development as a means by which access can be resolved has proved to be less than successful in ensuring that equity is achieved. This mechanism ensures that the institutional structure remains intact, while providing merely lip service to the imperatives of redress to which the government is committed. Academic development ensures that the real redress is relegated to the periphery of the institution. Use of academic development measures, while an important start, will simply amount to tinkering while the system is left intact. The extent of the transformational challenge suggests that much more needs to be done to address the problem if we are to come to terms with the salient issue of ensuring that institutions commit to the success of those whom they let in.

The issues of access, redress and equity dare not be forgotten, lest we undo the democratic gains made. It is evident that the seriousness with which equity needs to be achieved means that institutional transformation will need to become a reality. Ultimately, access is not a mere moral issue but a fundamentally material one. Not only do national development imperatives depend on it, but it is also likely to impact fundamentally on national productivity and prosperity. Earlier apartheid initiatives that were aimed exclusively at whites are an excellent example of policy commitment buttressed by a sustained investment in resources and policy alterations promoting greater access albeit for whites only. The difference in the present rendition is that it is motivated by the notion of inclusivity nested in a democratic cultural ethos: the opposite of the exclusionary practices of apartheid.

\section{NOTES}

1 Access is one of the criteria included in the accreditation of institutions of higher education by the council on higher education.

2 Current debates about matric results in South Africa ignore this.

3 Quite a striking resemblance to current debates about the restructuring of the senior certificate examination, and the imminent introduction of the General Education and Further Education Certificates. Attendant to this debate is the charge that 'standards' are being 
compromised, a position essentially premised on the notion that 'standards' are constant over time and unaffected by changing environmental imperatives. This proposition is not borne out by historical evidence. Standards are socially constructed and influenced by prevailing political sentiments at particular moments, international trends and so on.

4 A study by the Bureau for Educational and Social Research in 1962 found that 46 per cent of white students went into residential university (Malherbe 1977, 497). This was significant compared to the current national 15 per cent participation rate in 2002 as pointed out by George Subotzky Public Higher Education, in Human Resources Development Review, 2003: Education, Employment and Skills in South Africa, Human Sciences Research Council-HSRC (Cape Town and East Lansing, HSRC Press ands Michigan State University Press, 2003).

5 This was attempted at the University of the Witwatersrand but was abandoned ostensibly because the existing subsidy formulae could not accommodate it.

6 It was alleged that many HWIs (especially Historically Afrikaans Universities) were enrolling large numbers of black students in distance (called 'flexible') modes, with the result that campuses were 'White by day' and 'Black by night' (Department of Education 2001).

7 This situation sounds strikingly familiar to the white student experience during the apartheid era. Successive policy reforms virtually eliminated the high failure rates and substantially improved 'access with success'.

\section{REFERENCES}

Agar, D. 1990. Non-traditional students: perceptions of problems which influence academic success. Higher Education 19:435-454.

Badat, S. 2001. Introduction. In Kagisano CHE Higher Education Discussion Series. Johannesburg: Technikon SA. 1:1-6.

- 2001. Opening and Welcome by the Chief Executive of the CHE on occasion of the public launch of the Higher Education Quality Committee of the Council on Higher Education. Birchwood Conference Centre. Boksburg. 8 May.

—. 2003. Introductory address for the Master of Business Administration Re-Accreditation Consultative Workshop. February $20^{\text {th }}$ Council on Higher Education Office, Pretoria. Available at: http://www.che.ac.za. Accessed on 15 June 2004.

Bergquist, W. B. 1995. Quality through Access: Access with Quality. The new imperative for higher education. New Jersey: Prentice Hall.

Cherian, V. I. and L. Cherian, 1998. University students' adjustment problems. Psychological Reports 82:1135-1138.

Cloete, N. and I. Bunting. 2000. Higher education transformation: Assessing performance in South Africa. Pretoria: Centre for Higher Education Transformation (CHET).

Department of Education. 1997. Education White Paper 3: A programme for the transformation of higher education. Pretoria: Government Printer.

- 2001. The National plan for Higher Education. Available at http://www.polity.org.zq-. Accessed on 20 July 2004.

— 2002. A new institutional landscape for higher education in South Africa. Available at: http://education.pwv.gov.za/Media/Statements_2002/may02/he.htm. Accessed on 2 March 2003.

DoE, see Department of Education. 
Dowling, D. 1999. The policy of equity and redress and the problem of quality in research. Bulletin - News for the Human Sciences 5 (2): 10. Pretoria: HSRC Centre for Science Development.

Edigheji, O. 2005. Transformation needs to be forced on our reluctant universities. In Sunday Times, 5 June 2006. Available at: http://www.sundaytimes.co.za/Articles/TarkArticle.asp$\mathrm{x}$ ?ID=1498829. Accessed on 7 June 2006.

Eiselen, W. W. M. 1951. Report of Commission on Native Education 1945-51. Report UG. 53. Pretoria.

Harvey, L. and D. Green. 1993. 'Defining quality' assessment and evaluation. Higher Education 8 (1): 9-34.

Higgs, P., N. C. G. Vakalisa, T. V. Mda and N. Assie-Lumumba. (Eds.). 2000. African voices in education. Cape Town: Juta and Company.

HSRC, see Human Sciences Research Council.

Human Sciences Research Council. 2003. Education, employment and skills in South Africa. Cape Town and East Lansing: HSRC Press and Michigan State University press.

Kagee, A., T. Naidoo and N. Mahatey. 1997. Theoretical underpinnings of a student mentoring programme at a historically black university in South Africa. International Journal for the Advancement of Counselling 19 (3): 249-258.

Malherbe, E. G. 1965. Manpower training: Educational requirements for economic expansion. The South African Journal of Economics 33 (1): 29-51.

—. 1977. Education in South Africa 2:1923-75. Wynberg: Juta and Company.

Mphahlele, L. 2001. What is foundational about foundational programmes? Keynote speech given at the Science Foundation Programmes Indaba in Johannesburg. 1 June.

Nkomo, M. 1984. Student culture and activism in black South African universities: The roots of resistance. Cape Town, Westport: Greenwood Press.

- 1992. Democratizing higher education: Imperatives of quality and equality for development, quality and equality in higher education. In Proceedings of the Eighth Biennial Congress of the South African Association for Research and Development in Higher Education, pp. 68-85. University of the Orange Free State.

Pandor, N. 2005. Parliamentary address by Naledi Pandor. MP Minister of Education. Introducing the debate on the education budget vote. National Assembly, 17 May 2005, Cape Town.

Pirsig, R. M. 1974. Zen and the art of motorcycle maintenance. Morrow: New York.

Richardson, R. C. and E. Fisk-Skinner. 1991. Achieving quality and diversity: Universities in a multicultural society. New York: Macmillan Publishing Company.

Rossouw, H. 2001. South Africa spends \$163 Million a year on students who drop out. Chronicle of Higher Education.

Seepe, S. 1998. Towards an Afrocentric understanding. In Black perspectives on tertiary institutional transformation, ed. S. Seepe. Johannesburg: Vivlia Publishers and University of Venda.

- 1999. Africanization of knowledge, exploring mathematical and scientific knowledge embedded in African cultural practices. Cape Town: Juta and Company.

Sennett, J., G. Finchilescu, K. Gibson and R. Strauss. 2003. Adjustment of black students at a historically white South African University. Educational Psychology 23 (1):107-116.

Singh, M. 2001. Re-Inserting the 'public good' into higher education transformation. Kagisano CHE Higher Education Discussion Series. Vol. 1. Johannesburg: Pretoria. 
Subotzky, G. 2003a. Public higher education. In Human resources development review. Education, employment and skills in South Africa. Cape Town and East Lansing: HSRC Press and Michigan State University Press.

2003b. Public higher education, Human Sciences Research Council HRD Database. Available at: http://www.hsrcpublishers.ac.za/index.html/HRD.html-content. Accessed on 31 August 2004.

Van Heerden, E. 1995. Black university students in South Africa: The influence of sociocultural factors on study and performance. Anthropology and Education Quarterly 26:50-80.

Vroeijenstijn, T. A. 1995. Improvement and accountability: Navigating between Scylla and Charybdis. Guide for external quality assessment in higher education. London: Jessica Kingsley. 